\title{
A IMPORTÂNCIA de SER ELECTRÃo 0 Átomo E AS SUAS LIGAÇÕES: UM OLHAR SOBRE A EVOLUÇÃo DA QUíMICA
}

José Lopes da Silva e Palmira Ferreira da Silva

Gradiva

244 páginas * ISBN 978-989-616-345-7

ou a apologia da Química.

No prefácio, da autoria do Prof. Fraústo da Silva, é salientada a importância da Química e do enquadramento deste livro. "A Química como ciência exacta e as suas aplicações em áreas específicas, como, por exemplo, a Química da Vida e a Química Medicinal, são fundamentais, e este livro é um útil contributo para uma maior e melhor compreensão das potencialidades desta Ciência e da forma como a ela chegámos num longo percurso que se iniciou muito antes da nossa era e chegou aos dias de hoje, o que não é frequente encontrar em obras desta natureza, que normalmente se destinam a especialistas e são inacessíveis aos que o não são."

O livro descreve a "vida" do electrão na Química, como se ele fosse a personagem principal de uma "história" que começa antes de ele ser descoberto, do comportamento activo que passou a assumir e do papel que poderá ainda vir a desempenhar, em particular na procura de novos materiais, no contexto das Nanociências e da Química Supramolecular. Partindo de um enquadramento histórico, em que é descrita a evolução da nossa compreensão da estrutura da matéria até surgir a ideia de átomo, a verdadeira história começa de facto com a identificação dos seus constituintes, aparecendo então o electrão. A história evolui depois para a descrição das teorias e modelos de ligação química. Usando as moléculas, é feita uma introdução da forma como se racionalizam as propriedades dos materiais moleculares. Os modelos de ligação metálica, iónica e covalente, conducentes a agregados macroscópicos são também abordados. Por último, é feita uma abordagem de áreas de investigação e desenvolvimento actuais, em que a Química, e a nossa capacidade de preparar moléculas com estrutura e características novas e pedidas "à la carte", assume um papel preponderante. E, nesta perspectiva, esta obra transmite uma mensagem da inegável importância desta área do conhecimento no progresso científico e tecnológico, apesar de prevalecer hoje na sociedade uma percepção pouco positiva do seu impacto, em particular a nível ambiental.

É de referir que os autores, em particular o Prof. José Lopes da Silva, dedicaram muito tempo ao ensino de uma disciplina de Química Geral no Instituto Superior Técnico (IST), construindo uma verdadeira escola dentro do IST. Esta disciplina é comum à quase totalidade dos cursos do IST e, enquanto disciplina básica, pretende

\section{Jorge Morgado*}

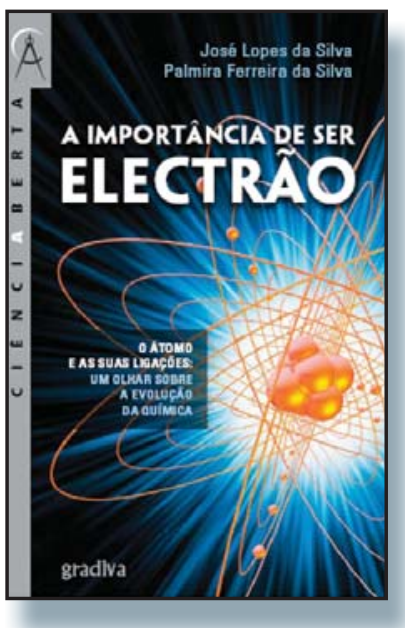

em particular mostrar que as propriedades dos materiais têm uma origem e podem ser racionalizadas, já que estão relacionadas com a constituição e estrutura desses mesmos materiais. O domínio deste conhecimento permite-nos desenvolver novos materiais, com novas propriedades. $\mathrm{E}$ isto nas várias áreas de especialização das engenharias. Esta obra nasce, pois, da perspectiva que os autores têm do papel da Química enquanto disciplina transversal do conhecimento e que espelha esse enquadramento. Por essa razão, os autores justificam a escolha da personagem "electrão" como ponto focal do texto, procurando "realçar a importância da sua descoberta para o desenvolvimento das teorias sobre a constituição e comportamento dos átomos e moléculas" e homenagear "uma partícula elementar que, ao contrário dos seus irmãos protão e neutrão, assim o é desde a sua descoberta".

Trata-se de uma obra de leitura muito fácil, em que a manifestada intenção de não incluir fórmulas, quase imprescindíveis desta área científica, foi bem conseguida, facilitando a sua leitura por parte de um público menos inserido nesta área. Para aqueles cuja actividade envolve ou se centra na Química, recomendo a sua leitura, pela perspectiva integrada que apresenta. Dada a dimensão e o carácter de obra 
de divulgação, consegue um bom equilíbrio entre o grau de desenvolvimento dos temas e a manutenção do interesse de um leitor menos conhecedor desta área do conhecimento. Pena é, no entanto, que, em particular a nível das ilustrações, haja algumas gralhas que bem merecem ser corrigidas numa futura reedição.

\section{Actualidades Científicas}

\section{Nanodiamantes como Catalisadores da Reacção de Produção de Estireno}

De acordo com uma equipa internacional de investigadores (Angew. Chem. Int. Ed., DOI: 10.1002/ anie.201002869), nanopartículas de diamante funcionam como catalisador de uma importante reacção industrial (produção de estireno) mais eficientemente e sob condições mais amenas que as necessárias com o catalisador comercial clássico baseado em metais de transição, tipicamente usado nesse processo. $O$ estudo sugere novas direcções para investigação fundamental sobre materiais catalíticos não metálicos e pode levar a melhorias na indústria petroquímica.

O estireno, um monómero muito utilizado para produzir poliestireno e vários copolímeros, é produzido principalmente por desidrogenação catalítica do etilbenzeno usando potássio/ óxido de ferro como catalisador. Para evitar a acumulação de coque, um material carbonoso que desactiva o catalisador, a reacção é conduzida a temperatura elevada na presença de um grande volume de vapor, tornando a desidrogenação do etilbenzeno um processo energeticamente intensivo.

A mudança de catalisador pode reduzir as necessidades energéticas do processo. Os químicos Jian Zhang,
Dang Sheng Su e Robert Schlögl, do Instituto Fritz Haber em Berlim, e seus colaboradores na China e na Croácia, descobriram que nanopartículas de diamante sujeitas a um tratamento ácido actuam como catalisador da desidrogenação do etilbenzeno, não acumulando coque, eliminando assim a necessidade da utilização de vapor no processo.

Para avaliar o novo catalisador, a equipa comparou o seu desempenho com o catalisador clássico de potássio/ óxido de ferro, na ausência de vapor. Após algumas horas de exposição ao etilbenzeno, a actividade catalítica do catalisador comercial diminuiu rapidamente e a sua superfície ficou revestida de coque. Em contraste, a superfície dos nanodiamantes permaneceu limpa após vários dias de exposição, e a sua actividade manteve-se constante durante um período de cerca de três vezes superior ao observado com o catalisador de ferro. O grupo descobriu também que o catalisador de nanodiamantes é significativamente mais activo que nanotubos de carbono, carvão activado e outros materiais de carbono.

A elevada actividade do catalisador provém da sua estrutura híbrida. Ba- seados em análises microscópicas e espectroscópicas, os investigadores descobriram que o seu procedimento de preparação produz partículas com um núcleo com cerca de $5 \mathrm{~nm}$, revestido por uma camada fina do tipo grafeno funcionalizada com cetonas, dicetonas e outros grupos funcionais contendo oxigénio que actuam como dadores de electrões, activando o alcano do etilbenzeno.

Catalisadores novos que oferecem desempenhos excelentes nos processos industriais de grande escala geram sempre interesse na comunidade da catálise, diz George J. Antos, um químico industrial reformado que dirige agora um programa de catálise da Fundação Nacional da Ciência dos EUA. Diz ainda, "Embora possamos questionar a viabilidade económica dos catalisadores de nanodiamante como substitutos dos catalisadores de ferro em quantidades industriais, o estudo tem um valor científico importante que pode conduzir ao desenvolvimento de novos catalisadores comerciais".

\section{(Adaptado de Chemical \& Engineering} News 2010, 88 (43) 9)

Helder Gomes (bquimica@ipb.pt) www.spq.pt

\section{Vá a www.spq.pt}

Torne-se Sócio da Sociedade Portuguesa de Química e beneficie de:

- Pertencer a uma comunidade científica dinâmica;

- Receber o boletim "QUÍMICA";

- Descontos nos Encontros promovidos pela SPQ;

- Descontos nas publicações da SPQ;

- Protocolos assinados entre a SPQ e outras entidades;

- Participar na promoção da Química;

- Apoiar uma Sociedade Científica. 